\title{
ASPECTOS QUÍMICOS NA INVESTIGAÇÃO DE ALGUNS TIPOS DE EFLORESCÊNCIAS EM BENS CULTURAIS
}

\author{
Isabela F. S. Santos ${ }^{\mathrm{a}, *,(\mathbb{C}}$, Thiago S. Puglieri ${ }^{\mathrm{a}, \mathrm{b}}$, Marcia S. Barbosa ${ }^{\mathrm{c}}$, Ana Cardoso ${ }^{\mathrm{d}}$, Tânia Rosado ${ }^{\mathrm{d}}$, Milene Gil ${ }^{\mathrm{d}}$, António \\ Candeias $^{\text {d e Dalva L. A. de Faria }}{ }^{a}$ \\ anstituto de Química, Universidade de São Paulo, 05508-000 São Paulo - SP, Brasil

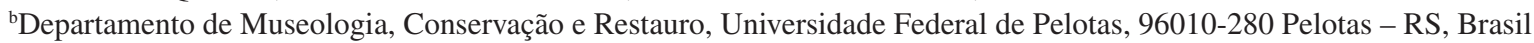 \\ 'Museu de Arte Contemporânea, Universidade de São Paulo, Av. 04094-050 São Paulo - SP, Brasil \\ 'Laboratório HERCULES, Universidade de Évora, Palácio do Vimioso,7000-809, Évora, Portugal
}

Recebido em 22/05/2019; aceito em 18/07/2019; publicado na web em 21/10/2019

\begin{abstract}
CHEMICAL ASPECTS IN THE INVESTIGATION OF SOME TYPES OF EFFLORESCENCE IN CULTURAL ASSETS. The preservation of Cultural Heritage is undoubtedly important for the society, and Conservation Science must dedicate itself to attempts to minimize the inherent processes of degradation to which cultural assets are susceptible. In this context, the evaluation of the chemical aspects of the composition of the objects and their relation with the environment where they are located are essential for the understanding of the decay signs observed, supporting the establishment of effective conservation strategies. These characteristics are demonstrated here by vibrational spectroscopy, scanning electron microscopy and microbiological analysis of efflorescences observed in two types of paintings: a tempera on canvas painting ("Barco com bandeirinhas e pássaros", Alfredo Volpi, 1955) and an oil mural painting of the Throne Room of the National Palace of Mafra (18th-19th century, Mafra, Portugal). The challenges involved in the investigation of the efflorescences are demonstrated in both cases, suggesting the occurrence of degradation processes of different origins: in Alfredo Volpi's tempera on canvas painting, the migration of substances from the preparation layer to the surface of the pictorial layer and microbiological colonization; and in the mural painting the migration of calcium salts from the constituent materials of plaster and of neoformation, besides associated microbiological colonization.
\end{abstract}

Keywords: efflorescence; degradation; conservation science; Raman spectroscopy.

\section{INTRODUÇÃO}

A relação que a humanidade estabelece com seu Patrimônio Cultural na busca pela sua preservação pode ser compreendida como uma maneira de garantir a manutenção da memória, história e expressões artísticas que, entre outros elementos, constitui a identidade de um povo. É nesse contexto que se insere a Ciência do Patrimônio (Heritage Science) definida como "um domínio interdisciplinar de pesquisa, que engloba as ciências humanas, exatas e biológicas. Ela objetiva aumentar o entendimento, cuidado, uso e gerenciamento tanto do patrimônio cultural tangível quanto intangível, de modo a enriquecer a vida das pessoas hoje e no futuro" (ICCROM, 2019). ${ }^{1}$

Quando se consideram as características materiais dos bens que, como qualquer material, são susceptíveis ao decaimento e à degradação ao longo do tempo, o emprego do conhecimento e de métodos típicos das ciências naturais na definição de estratégias de preservação ganha grande importância, com a Química exercendo um papel crucial na compreensão de processos físico-químicos de interação e transformação dos materiais.

É difícil precisar quando princípios e métodos científicos começaram a ser usados na tentativa de preservação ou restauração de bens culturais materiais. Um dos registros mais antigos é mencionado no levantamento feito por Caldararo, ${ }^{2}$ que aponta experimentos químicos feitos já no final do Séc. XVIII visando a restauração de papel, pergaminho e papiro. Somente mais tarde, no entanto, ao que se estima corresponder à segunda metade do século $\mathrm{XX},{ }^{3}$ que a percepção de aprimorar e buscar novos métodos para a conservação e restauração desses bens foi aflorada.

*e-mail: isafsodre@gmail.com
Frequentemente, a composição material de um dado objeto de interesse histórico e cultural apresenta elevada complexidade química, como é o caso de pinturas cujas técnicas utilizadas para a sua confecção envolvem diferentes materiais orgânicos e inorgânicos. Uma consequência disso é que as características de decaimento observadas nesses materiais podem ser resultado de sucessivos processos de degradação (químicos, físicos ou biológicos) ao longo do tempo. ${ }^{4}$ Esses aspectos trazem a necessidade de que investigações em Patrimônio levem em conta não somente as possibilidades de interação entre diferentes espécies químicas, como também aspectos sinérgicos entre os constituintes da obra e/ou deles com o microambiente ${ }^{5}$ que potencialmente influenciam o desencadeamento dos fenômenos físico-químicos responsáveis pela degradação.

Do ponto de vista químico, o termo "eflorescência" é adequado para descrever a deposição de substâncias na superfície de materiais que resulta da migração de espécies da sua composição. Um exemplo são as eflorescências salinas, como são tradicionalmente classificados em conservação arquitetônica o produto da migração de sais inorgânicos solúveis em materiais de construção (devido a variações termo-higrométricas que induzem ciclos de cristalização-dissolução dos sais). ${ }^{6}$ Apesar dessa especificidade observa-se que, especialmente no Brasil, este termo tem sido empregado na Conservação-Restauração e na Ciência da Conservação de maneira abrangente para descrever alterações que comprometem o aspecto original da superfície dos objetos. Dentre a diversidade de alterações que tem sido tratada como eflorescências, podem ser citados os fenômenos de embranquecimento de superfícies, aparecimento de pátinas, opacidade, alterações decorrentes da migração e segregação de ácidos graxos livres, de sabões metálicos, crescimento de micro-organismos, entre outros. ${ }^{6-10}$

Se por um lado o termo "eflorescência" tem sido empregado de 
maneira ampla para descrever diversos tipos de alterações, por outro observa-se um esforço de característica multidisciplinar na tentativa de introduzir terminologias que possam discriminar os processos de degradação envolvidos em cada tipo de decaimento observado. São exemplos de termos frequentemente encontrados na literatura em inglês: blanching (ruptura física da superfície da camada pictórica), blooming (migração de compostos da composição da pintura e deposição em sua superfície); sweating (migração de ácidos graxos livres ou sabões metálicos da composição de tintas); bleaching (perda de coloração observada em pigmentos); crazing, micro-fissures, microcracking ou micro-voids (fissuras na camada de tinta); mold ou mildew (crescimento de micro-organismos na superfície da obra); transferred images ou ghost images (migração de componentes de pinturas protegidas com vidro, com posterior deposição dessas substâncias no lado de dentro do vidro protetor); e white surface depositions (exsudatos). ${ }^{11}$ Nesse contexto, a necessidade de buscar um termo adequado para descrever fenômenos específicos está intimamente ligada à capacidade de compreensão dos processos de degradação em curso, uma vez que somente a partir de um diagnóstico preciso é que se torna possível o estabelecimento de efetivas estratégias de mitigação de danos, como conduzido em estudo anterior acerca de uma pintura de Emmanuel Nassar. ${ }^{12}$

A importância da avaliação dos aspectos químicos para a compreensão do surgimento de eflorescências será demonstrada no presente trabalhado com a investigação de eflorescências observadas em pinturas produzidas por duas diferentes técnicas: a pintura "Barco com bandeirinhas e pássaros" (têmpera, 1955) de Alfredo Volpi, pertencente ao Museu de Arte Contemporânea da Universidade de São Paulo (MAC-USP), e a pintura mural da Sala do Trono do Palácio Nacional de Mafra (Mafra, Portugal), elaborada entre 1796 a 1807, por diferentes artistas, com técnicas de secco e fresco. As duas são técnicas de pintura mural. No secco (ou fresco-secco) os pigmentos são aplicados diretamente sobre a superfície seca, enquanto no fresco a superfície ainda está úmida e, nesse caso, o veículo para o pigmento é a água, permitindo a incorporação da tinta ao mural.

O estudo das eflorescências na pintura "Barco com bandeirinhas e pássaros" foi motivado pelo embranquecimento gradativo que vinha sendo observado na obra pela equipe técnica do MAC-USP. Já a investigação das eflorescências na pintura mural do Palácio Nacional de Mafra foi capitaneada pelo Laboratório de Herança Cultural, Estudos e Salvaguarda (HERCULES) da Universidade de Évora, responsável pela caracterização material dos eventos associados à degradação (eflorescências associadas a perdas de camada pictórica) observada em algumas regiões da pintura.

\section{PARTE EXPERIMENTAL}

\section{Amostragem}

A inspeção visual da pintura "Barco com Bandeirinhas e Pássaros" (Figura 1 - à esquerda) revelou a presença de um material esbranquiçado, recobrindo toda a área azul da superfície da camada pictórica. Devido ao aspecto de embranquecimento, esse material foi denominado, a princípio, eflorescência, cabendo à investigação confirmar sua origem e natureza.

As amostras de eflorescências da obra "Barco com Bandeirinhas e Pássaros" foram coletadas assegurando um procedimento minimamente invasivo na obra. A investigação foi realizada em duas etapas; a primeira em 2013 e a segunda em 2015. O material coletado na primeira amostragem é mostrado à direita da imagem apresentada na Figura 1, constituindo material branco e macio, que foi facilmente removido da superfície da camada pictórica com o auxílio de uma lâmina de bisturi (sem afetar a superfície da obra). O material coletado foi armazenado em tubo eppendorf® para posterior análise.

Além do material eflorescente, uma microamostra (entre $100 \mathrm{e}$ $150 \mu \mathrm{m}$ ) de camada pictórica na região azul foi coletada, assegurando procedimento virtualmente não invasivo, o que foi feito com o auxílio de lâmina de bisturi para garantir a retirada de fragmento com dimensões micrométricas e em áreas de borda do quadro. A amostra coletada foi acondicionada em tubo eppendorf® e denominada Azul1.

A segunda amostragem (2015) foi realizada para estudos mais aprofundados. As áreas de amostragem foram cuidadosamente selecionadas com o auxílio de uma lente objetiva acoplada à câmera de um aparelho celular, que permitiu identificar os locais com maior quantidade de eflorescência.

Após inspeção, a coleta foi feita com o contato suave de fitas adesivas de carbono (da marca Ted Pella, Inc.) sobre suporte metálico de alumínio (stub) em 8 diferentes regiões da pintura (regiões de cor azul e vermelha), aplicando e retirando a fita de carbono da superfície da camada pictórica para a retenção de material. A fita de carbono foi escolhida por representar menores riscos à integridade da pintura, uma vez que, diferente do observado na primeira coleta, o material eflorescente apresentou maior dureza e adesão à superfície.

Uma inspeção (com microscópio portátil) das áreas de coleta após a amostragem foi feita para assegurar que não restou cola da fita adesiva de carbono na superfície da camada pictórica. O material coletado foi então armazenado em placas de Petri em temperatura ambiente para posterior análise.

Além do material eflorescente, uma microamostra de camada pictórica na região vermelha (entre 100 e $150 \mu \mathrm{m}$ ) foi coletada
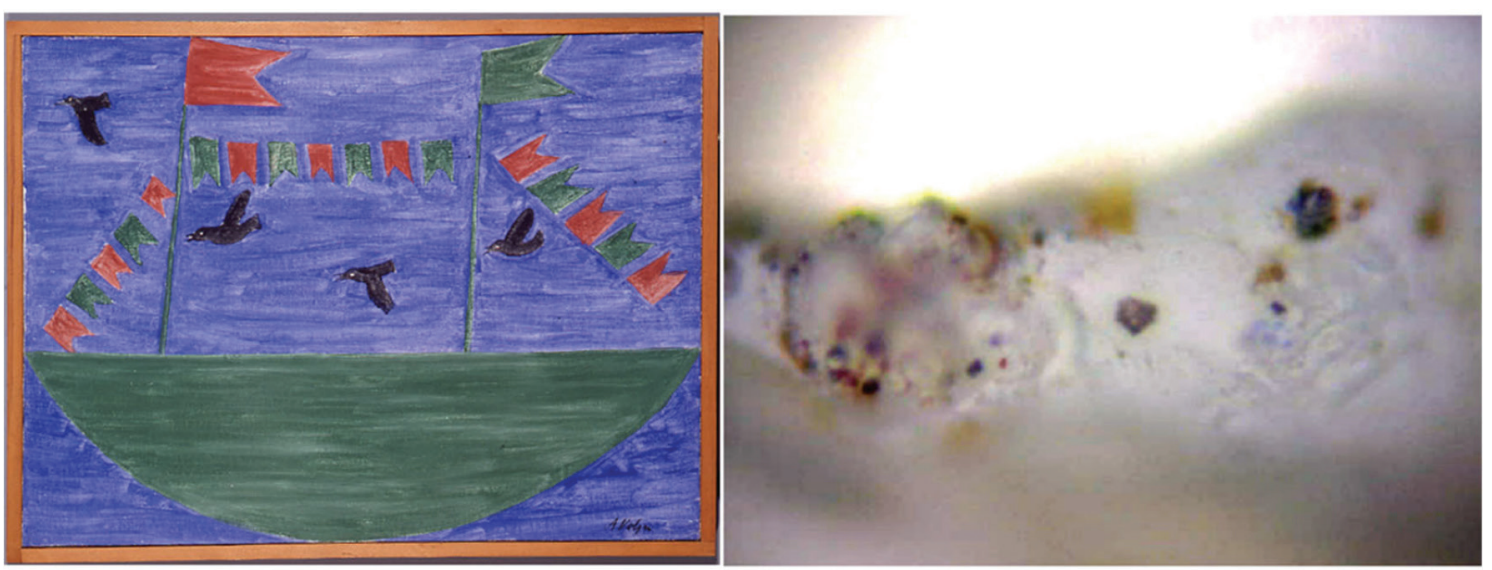

Figura 1. À esquerda, fotografia da pintura "Barco com bandeirinhas e pássaros" (fotografia de Marília Bovo Lopes, 2019), de Alfredo Volpi (1955). À direita, imagem feita em microscópio óptico com aumento de x200 obtida do material eflorescente coletado 
assegurando procedimento virtualmente não invasivo, o que foi feito com o auxílio de lâmina de bisturi para garantir a retirada de fragmento com dimensões micrométricas. A amostra coletada foi acondicionada em tubo eppendorf® e denominada Vermelho1.

Para a investigação do processo de degradação observado na pintura mural da Sala do Trono do Palácio Nacional de Mafra, microfragmentos da camada pictórica da zona com sinais de degradação (pontos de coleta indicados na Figura 2-acima) foram coletados com o auxílio de lâminas de bisturi, e posteriormente acondicionados em tubos eppendorf ${ }^{\circledR}$ e frascos plásticos. As amostras coletadas foram denominadas VermP (vermelho), AmP (amarelo), VP (verde) e AP (azul).
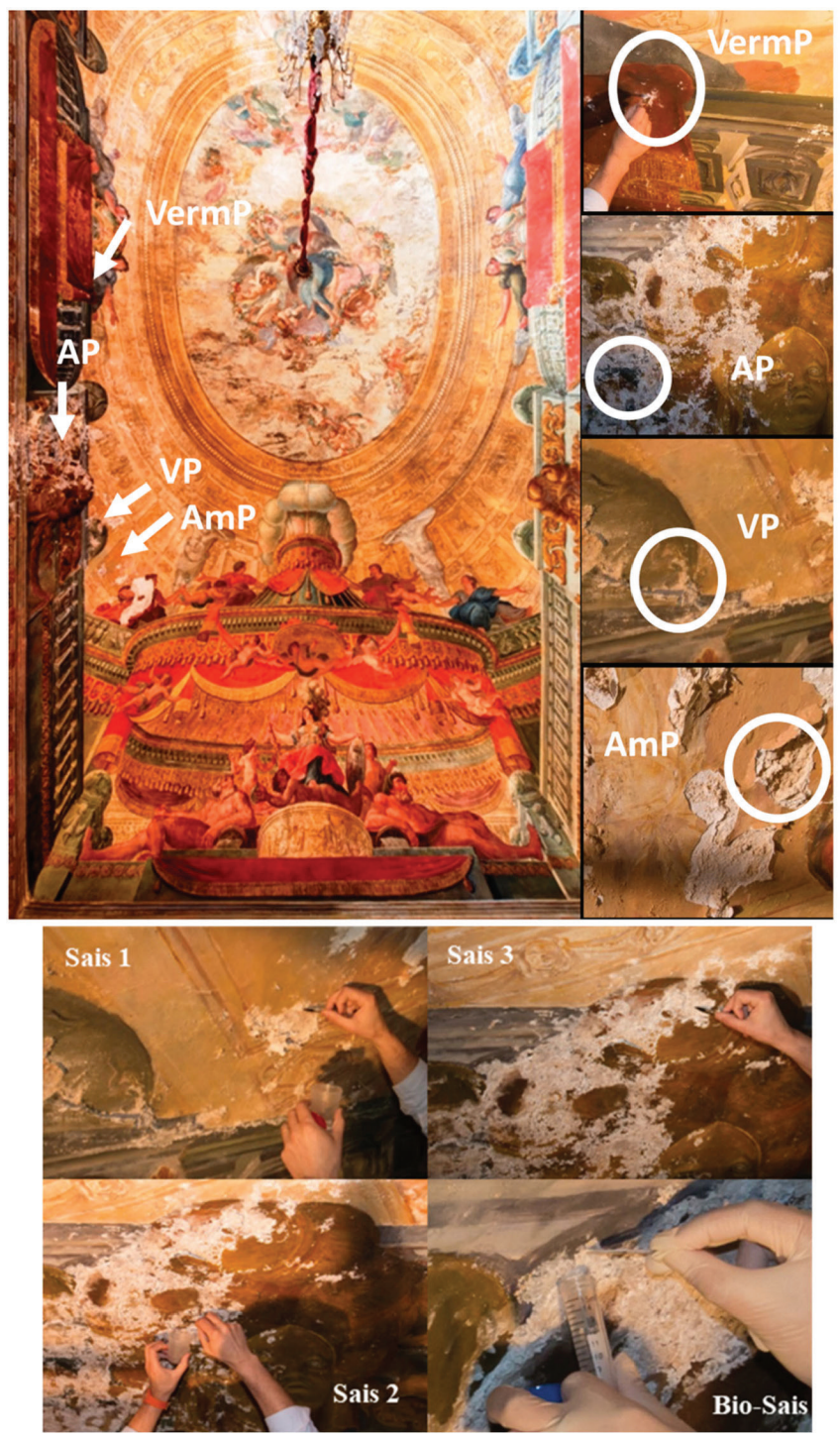

Figura 2. Acima, zonas de amostragem da pintura mural da Sala do Trono do Palácio Nacional de Mafra, Portugal (fotografia de Sofia Lopes, 2017). Detalhes das áreas degradadas estão mostradas no painel à direita. As definições das siglas usadas (VermP, AP, VP e AmP) são dadas no texto; abaixo, amostragem das eflorescências observadas na pintura

Amostras de material eflorescente nas regiões degradadas foram coletadas em 3 diferentes pontos da pintura (Sais 1, Sais 2 e Sais 3, Figura 2-abaixo), e acondicionadas em tubos eppendorf® para posterior análise. Por fim, uma amostra de eflorescências para análise microbiológica foi coletada da região degradada e denominada BioSais (local de coleta na Figura 2-abaixo). A coleta de amostra para a análise microbiológica foi realizada em condições de semiassepsia, utilizando hastes de algodão, bisturis e microtubos estéreis, transportadas e conservadas em meio apropriado até posterior utilização.

\section{Reagentes}

O teste colorimétrico de Biureto foi utilizado para detectar proteínas na eflorescência da pintura "Barco com bandeirinhas e pássaros", de acordo com o procedimento descrito na literatura: ${ }^{13} 0,15 \mathrm{~g}$ de sulfato de cobre (II) $\left(\mathrm{CuSO}_{4} \cdot 5 \mathrm{H}_{2} \mathrm{O}\right.$, Sigma-Aldrich) e $0,6 \mathrm{~g}$ de tartarato duplo de sódio e potássio $\left(\mathrm{KNaC}_{4} \mathrm{H}_{4} \mathrm{O}_{6} \cdot 4 \mathrm{H}_{2} \mathrm{O}\right.$, Sigma-Aldrich) foram dissolvidos em $50 \mathrm{~mL}$ de água deionizada; sob agitação constante, adicionaram-se $30 \mathrm{~mL}$ de solução aquosa de $\mathrm{NaOH}$ (Synth) $10 \%$ e $0,1 \mathrm{~g}$ de iodeto de potássio (KI, Merck) à solução; o volume foi então completado com água deionizada para $100 \mathrm{~mL}$. O teste foi realizado pela adição de $100 \mu \mathrm{L}$ do reagente de Biureto sobre a eflorescência. O teste se baseia na mudança de coloração da solução para violeta ao contato com a amostra, o que confirma a presença de proteína.

$\mathrm{Na}$ preparação dos meios de cultura, foram usados MRD (Maximum Recovery Diluent, Merck), NA (Nutrient Agar, $\mathrm{pH} 7,4 \pm 0,2 \mathrm{a} 25^{\circ} \mathrm{C}$ ), MEA (Malt Extract Agar, pH 5,5 $\pm 0,3$ a $25^{\circ} \mathrm{C}$ ) e ASM-1 (purificado, HiMedia). Os cortes estratigráficos foram preparados em resina epoxy (Epofix Fix) da Struers A/S.

Os padrões de substâncias proteicas utilizados são de uso corrente em bens culturais e foram cedidos pelo MAC-USP.

\section{Análise microbiológica}

As amostras microbiológicas coletadas da pintura mural da Sala do Trono do Palácio Nacional de Mafra foram encaminhadas para o isolamento de população biológica e caracterização dos isolados. Para o isolamento de população biológica, previamente as amostras recolhidas com hastes de algodão foram colocadas sob agitação durante $24 \mathrm{~h}$ para promover a extração das células. Após este processo foram realizadas diferentes diluições (1:10 a 1:1000) em $\mathrm{NaCl}$ 0,9\% e as amostras foram inoculadas em diferentes meios, específicos para cada grupo de micro-organismos: NA para bactérias, MEA para fungos filamentosos e ASM-1 para cianobactérias e algas. As culturas foram incubadas a $30^{\circ} \mathrm{C}$ durante $24-48 \mathrm{~h}$ para desenvolvimento de bactérias, durante 4-5 dias a $28^{\circ} \mathrm{C}$ para crescimento de fungos e à temperatura ambiente com exposição direta à luz solar para desenvolvimento de cianobactérias e algas. Em seguida, replicagens das diferentes colônias desenvolvidas foram efetuadas até obtenção de culturas puras. Os isolados puros obtidos foram conservados em rampas e guardados a $4{ }^{\circ} \mathrm{C}$. Todos os procedimentos descritos acima foram realizados em condições de assepsia. ${ }^{14}$ As placas foram mantidas em incubação para verificar desenvolvimento de micro-organismos com metabolismo mais lento. A identificação dos isolados microbianos foi efetuada com base na observação das características macroscópicas e microscópicas, tais como textura e coloração das colônias, morfologia das hifas e estruturas reprodutoras (no caso dos isolados esporulados). As preparações foram coradas com azul de lactofenol, observadas em microscópio óptico (Motic BA410E) e fotografadas (câmara fotográfica Moticam Pro 282B, com resolução de 5 MP).

\section{Instrumentação}

Os espectros Raman obtidos no estudo da pintura "Barco com bandeirinhas e pássaros" foram registrados com linha de excitação em 785 nm (laser de diodo, Renishaw) em microscópio Raman Renishaw inVia Reflex, equipado com câmera CCD (Renishaw, 600x400 pixels) termoeletricamente refrigerado $\left(-70{ }^{\circ} \mathrm{C}\right)$ e acoplado a um microscópio Leica modelo DM2500 M; foi utilizada rede de difração de 
1200 linhas/mm. As áreas sondadas nas amostras foram escolhidas utilizando lente objetiva Leica x50 (NA 0,75) e a potência de laser utilizada foi mantida em valores seguros para evitar a degradação dos materiais analisados; esses valores foram determinados a partir de testes prévios, assumindo como seguros os valores de potência para os quais não foram observadas variações no perfil espectral nem de coloração das regiões analisadas. No caso específico das análises de material eflorescente, as análises foram feitas diretamente nas lâminas de bisturi. Os espectros Raman das amostras da camada pictórica da pintura mural da Sala do Trono do Palácio Nacional de Mafra foram obtidos utilizando microscópio Raman Horiba Xplora, com linha de excitação em $785 \mathrm{~nm}$ (laser de diodo). As áreas sondadas nas amostras foram escolhidas utilizando-se lente objetiva x 50 (NA 0,75) e a potência do laser foi mantida em valores seguros para evitar a degradação dos materiais, como descrito acima.

As micrografias SEM de fragmentos da pintura "Barco com bandeirinhas e pássaros" foram obtidas utilizando microscópio eletrônico de varredura JEOL modelo JCM-500 NeoScope ( $5 \mathrm{kV}$, detector LEI, distância de trabalho de $8 \mathrm{~mm}$ ), e FEI modelo Quanta FEG $650(30 \mathrm{kV}$, detector ETD, distância de trabalho de 6,6 mm). Com a finalidade de melhorar a qualidade das micrografias, foram realizadas deposições de ouro ou platina, por sputtering, em todas as amostras, de modo a evitar o acúmulo de carga na superfície analisada.

As imagens de microscopia óptica $(\mathrm{OM})$ dos cortes estratigráficos da camada pictórica da pintura mural da Sala do Trono do Palácio Nacional de Mafra foram registradas em microscópio óptico Leica DM2500 M com luz refletida e campo escuro (DF), com magnificação de $\mathrm{x} 100$ e x200.

Os espectros $\mu$-FTIR das amostras da camada pictórica da pintura mural da Sala do Trono do Palácio Nacional de Mafra foram registrados utilizando-se espetrômetro Bruker, modelo Tensor 27, operando na região do infravermelho médio (MIR), com detector MCT (Mercury Cadmium Telluride), acoplado a microscópio Hyperion 3000 controlado pelo software OPUS 7.2 (Bruker Optik). As amostras foram analisadas no modo de transmissão utilizando uma objetiva de x15 e uma microcélula de compressão de diamante Diamond EX'Press cell (abertura de 1,6 mm). Todos os espectros foram registrados com 64 varreduras e resolução espectral de $4 \mathrm{~cm}^{-1}$.

As análises de $\mu$-XRD das amostras da pintura mural da Sala do Trono do Palácio Nacional de Mafra foram realizadas com difratômetro da marca Bruker modelo AXS D8 usando a radiação $\mathrm{K} \alpha$ do cobre (40 kV, $40 \mathrm{~mA}$ ), espelho Göebel, colimador de $1 \mathrm{~mm}$, detector linear LYNXEYE (192 detectores individuais). Os padrões de difração foram obtidos em um intervalo $(2 \theta)$ de $5-75^{\circ}$, com passo de $0,05^{\circ}$ por segundo.

As soluções do preparo do reagente de Biureto foram feitas com água deionizada por ultrapurificador da marca USF Elga Máxima.

\section{RESULTADOS E DISCUSSÃO}

Dentre as principais vantagens do uso das técnicas de microscopia vibracional em bens culturais, destaca-se o seu caráter não destrutivo e o fato de requererem amostras de dimensão micrométrica para a realização das análises, atendendo às necessidades de preservação dos bens.

$\mathrm{Na}$ investigação das eflorescências na pintura "Barco com bandeirinhas e pássaros", por se tratar de uma obra em têmpera (confeccionada pela mistura de aglutinantes proteicos e pigmentos), tanto a possibilidade de se tratar da migração de substância aglutinante do meio, quanto da colonização de micro-organismos (biodeterioração devido à presença de material proteico) foram, primeiramente, consideradas. Nessa etapa, a análise prévia por microscopia óptica permitiu descartar a hipótese de biodeterioração, porque as estruturas características dos diversos tipos de micro-organismos não foram observadas.

O espectro Raman obtido da amostra de eflorescência coletada (Figura 3) apresenta principais bandas em 1666, 1445, 1367, 1309, $1097,1086,999$ e $636 \mathrm{~cm}^{-1}$, com os conjuntos de bandas em 1086, 710 e $298 \mathrm{~cm}^{-1}$, e 1097,723 e $280 \mathrm{~cm}^{-1}$ atribuídos a carbonato de cálcio $\left(\mathrm{CaCO}_{3}\right)$ e a carbonato duplo de cálcio e magnésio $\left(\mathrm{CaMg}\left(\mathrm{CO}_{3}\right)_{2}\right)$, respectivamente. ${ }^{15,16}$ Os espectros Raman atribuídos a $\mathrm{CaCO}_{3} \mathrm{e}$ $\mathrm{CaMg}\left(\mathrm{CO}_{3}\right)_{2}$ reportados são, na ordem citada, compatíveis com a forma calcita e dolomita desses compostos.

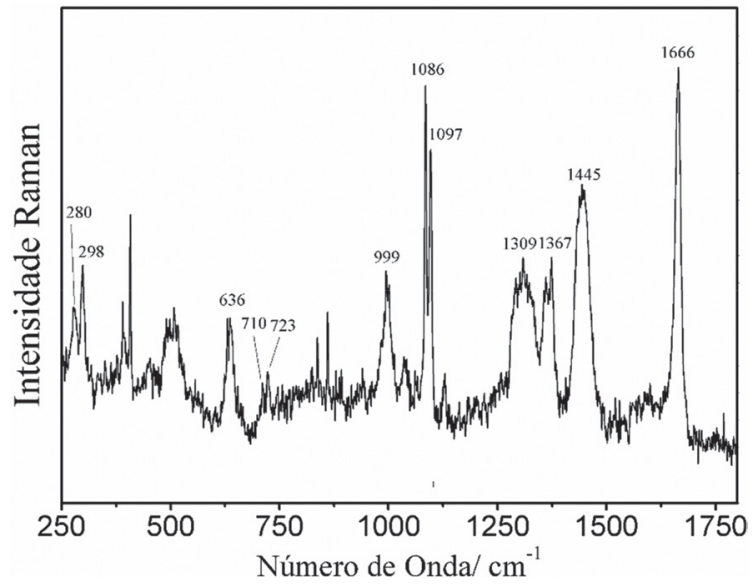

Figura 3. Espectro Raman $\left(\lambda_{0}=785 \mathrm{~nm}\right)$ da amostra de eflorescência coletada da obra "Barco com bandeirinhas e pássaros", de Alfredo Volpi. A linha base foi corrigida usando múltiplos pontos

De acordo com o relatado pelo próprio artista, Alfredo Volpi, em entrevistas, ${ }^{17,18}$ a camada de preparação de suas telas consistia na mistura de gelatina com carbonato de cálcio ou cola animal (de coelho ou porco) misturada com gesso $\left(\mathrm{CaSO}_{4} \cdot 2 \mathrm{H}_{2} \mathrm{O}\right)$, e no preparo de suas tintas, além da base de ovo e pigmentos, uma mistura de Dammar (resina triterpênica, de origem vegetal), terebintina (exsudato resinoso extraído de plantas coníferas) e óleo de cravo era adicionada. Considerando essas informações, o espectro Raman do material eflorescente foi comparado com espectros de padrões dos materiais proteicos empregados pelo artista (Figura 4 - acima): gelatina, ovoalbumina e cola de boi (colágeno). A comparação dos espectros revelou que não há correspondência entre o material eflorescente coletado (Figura 4a) com nenhum dos padrões analisados individualmente (Figura 4b, 4c e 4d). Especificamente no caso de proteínas, alterações no perfil espectral devido ao envelhecimento ${ }^{19}$ ou a interações com as demais substâncias presentes no meio, são esperadas. $\mathrm{Na}$ literatura, o deslocamento de bandas vibracionais (verificado por espectroscopia de absorção no infravermelho) de proteínas após a interação com carbonato de cálcio é descrito e atribuído à mudança de conformação da estrutura tridimensional da molécula. ${ }^{20}$ Devido à presença de carbonato de cálcio na eflorescência da obra em estudo (Figura 3, banda principal em $1086 \mathrm{~cm}^{-1}$ ) e à identificação de proteína pelo teste de Biureto, essa possibilidade foi considerada, porém, ainda assim não houve coincidência entre o espectro da eflorescência e o de proteínas.

Foi também considerada a hipótese do material eflorescente corresponder à mistura de aglutinantes proteicos com outros compostos, incluindo resina Dammar e terebintina. Apesar do padrão espectral da eflorescência não coincidir com o da resina Dammar, as regiões em que suas principais bandas Raman foram observadas são coincidentes $\left(1655,1450\right.$ e $\left.710 \mathrm{~cm}^{-1}\right),{ }^{21}$ sugerindo a presença de algum tipo de resina na composição da eflorescência. A identificação da resina, no entanto, não pode ser feita tanto devido ao fato de que Volpi pode 

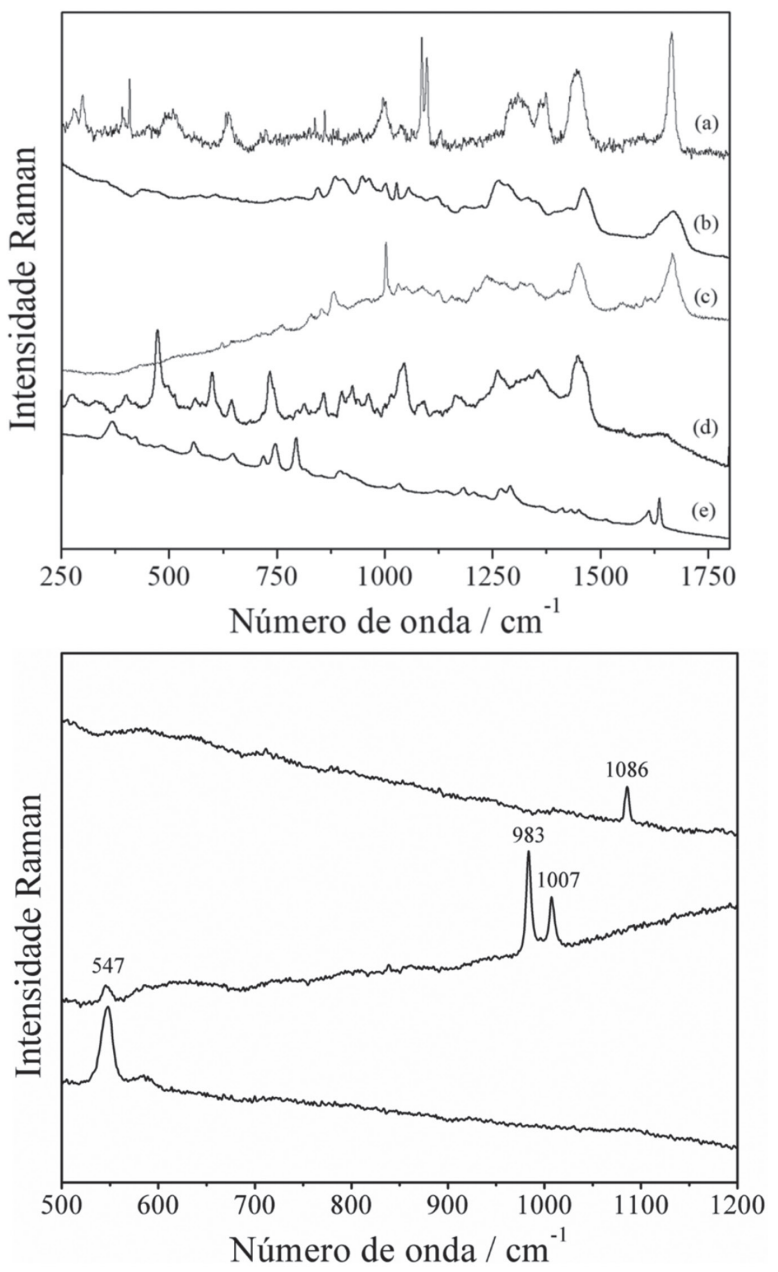

Figura 4. Acima: (a) Espectros Raman $\left(\lambda_{0}=785 \mathrm{~nm}\right)$ da eflorescência coletada da obra "Barco com bandeirinha e pássaros", e dos padrões de (b) gelatina, (c) ovoalbumina, (d) cola de boi e (e) eugenol; abaixo: espectros Raman $\left(\lambda_{0}=785 \mathrm{~nm}\right)$ em diferentes pontos da amostra de eflorescência coletada da obra "Barco com bandeirinha e pássaros"

ter usado alguma substância não usual na sua formulação, quanto considerando processos de degradação que reconhecidamente podem alterar a composição química das substâncias ao longo do tempo. A presença de eugenol (espectro mostrado na Figura 4e) e terebintina pode ser descartada pela ausência de bandas características desses compostos no espectro da eflorescência.

Ao sondar pontos com diferentes colorações na amostra de eflorescência (na inspeção com microscópio óptico, à direita na Figura 1), diferentes espectros foram obtidos (Figura 4 - abaixo), com a banda em $1007 \mathrm{~cm}^{-1}$ podendo ser atribuída a $\mathrm{CaSO}_{4}$; essa é a banda mais intensa do sulfato de cálcio, as outras localizadas em aproximadamente 420, 495, 620 e $1039 \mathrm{~cm}^{-1}$ não são observadas ${ }^{22}$ devido ao intenso fundo de luminescência do espectro. Da mesma forma, as principais bandas observadas em 547 e $585 \mathrm{~cm}^{-1}$ foram atribuídas ao pigmento azul ultramarino, ${ }^{23}$ e em $983 \mathrm{~cm}^{-1}$ atribuída ao $\mathrm{BaSO}_{4} \cdot{ }^{24}$ Ambos os materiais identificados pelos espectros mostrados na Figura 4-abaixo são tipicamente usados para a produção de tintas ou na camada de preparação de pinturas a têmpera.

Tendo em conta a prática do artista, a detecção de proteína pelo teste do Biureto e a identificação de carbonato de cálcio por espectroscopia Raman, indicam a migração de componentes da camada de preparação da tela para a superfície da camada pictórica.

Espectros Raman do fragmento da camada pictórica azul (Azul1) da pintura "Barco com bandeirinhas e pássaros" (não mostrados), confirmaram apenas o uso de $\mathrm{BaSO}_{4}$ e azul ultramarino na camada pictórica e a não observação de bandas características de $\mathrm{CaCO}_{3}$, $\mathrm{CaMg}\left(\mathrm{CO}_{3}\right)_{2}$ e $\mathrm{CaSO}_{4}$, reforça a interpretação de que esses sais de cálcio encontrados na amostra de eflorescência sejam provenientes da camada de preparação.

Após o período aproximado de dois anos, uma segunda coleta de amostras foi realizada com o objetivo de complementar os resultados obtidos. Além do embranquecimento da camada pictórica azul, verificado na primeira coleta (2013), a inspeção prévia da pintura também revelou o embranquecimento de regiões de camada pictórica vermelha (indicado à esquerda na Figura 5). Diferente do material coletado na primeira amostragem (de textura macia e levemente aderido à superfície), as eflorescências observadas na segunda coleta apresentaram características distintas, com maior dureza e forte adesão à superfície.

A análise do pigmento vermelho (amostra Vermelho1) revelou a presença do pigmento vermelho hematita $\left(\alpha-\mathrm{Fe}_{2} \mathrm{O}_{3}\right.$, bandas características em 224, 290, 408, 495, 610, e $1316 \mathrm{~cm}^{-1}$ ) na composição da camada pictórica, além de $\mathrm{BaSO}_{4}\left(982 \mathrm{~cm}^{-1}\right)$ e $\mathrm{CaSO}_{4}\left(1006 \mathrm{~cm}^{-1}\right)$, como mostrado à direita na Figura 5.

Como as amostras de eflorescência apresentaram grande luminescência na análise Raman (o que impediu a obtenção de informações químicas), os materiais amostrados em fitas de carbono, previamente
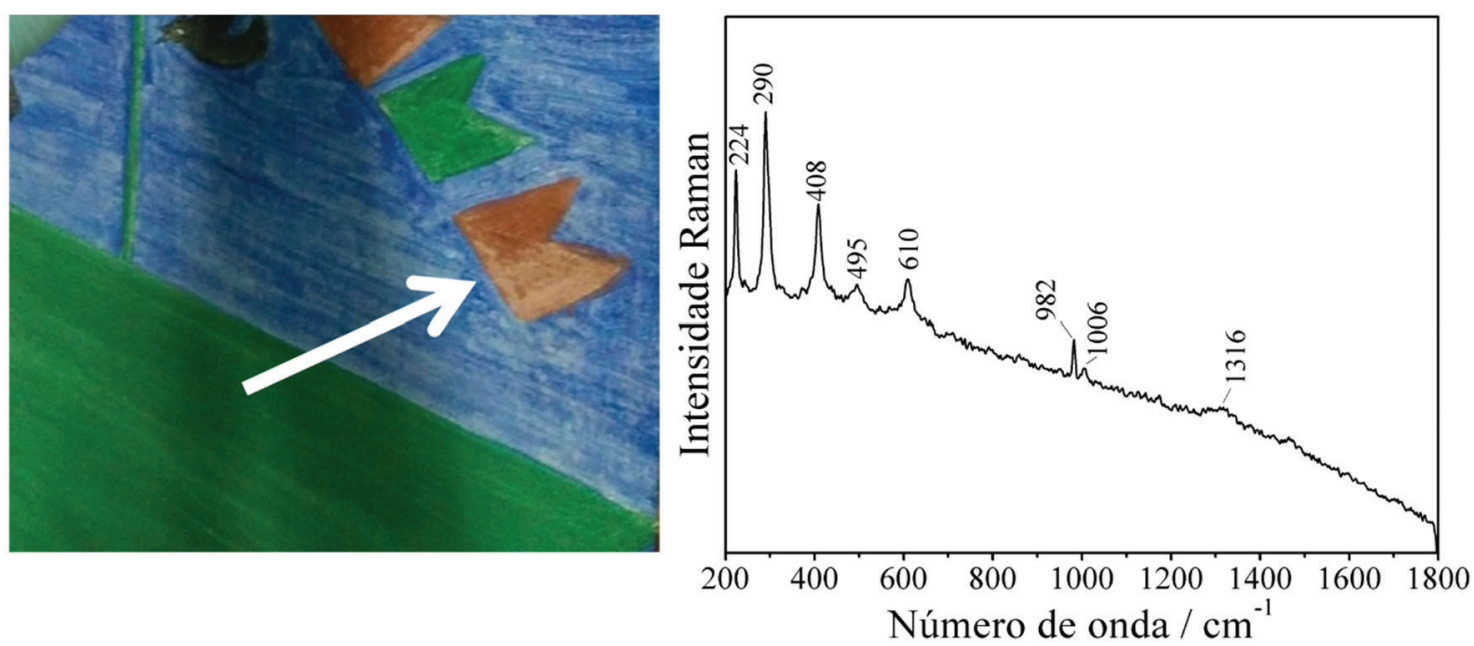

Figura 5. À esquerda, fotografia evidenciando o embranquecimento da camada pictórica vermelha na pintura "Barco com bandeirinhas e pássaros", verificada na segunda etapa de investigação. À direita, espectro Raman médio obtido para o fragmento de camada pictórica vermelha (Vermelhol) 
recobertos por ouro para a análise SEM, foram analisados por microscopia Raman. Essa estratégia é justificada pela esperada supressão de luminescência de substâncias em contato com partículas metálicas (nesse caso, ouro). ${ }^{25}$ Como resultado, das 8 amostras em stubs (8 diferentes áreas de coleta), apenas uma das amostras coletadas (denominada Eflorescência_Azul2) apresentou espectro Raman (Figura 6), mostrando um perfil bastante similar ao verificado para leveduras ${ }^{26}$ apesar da baixa razão sinal/ruído.

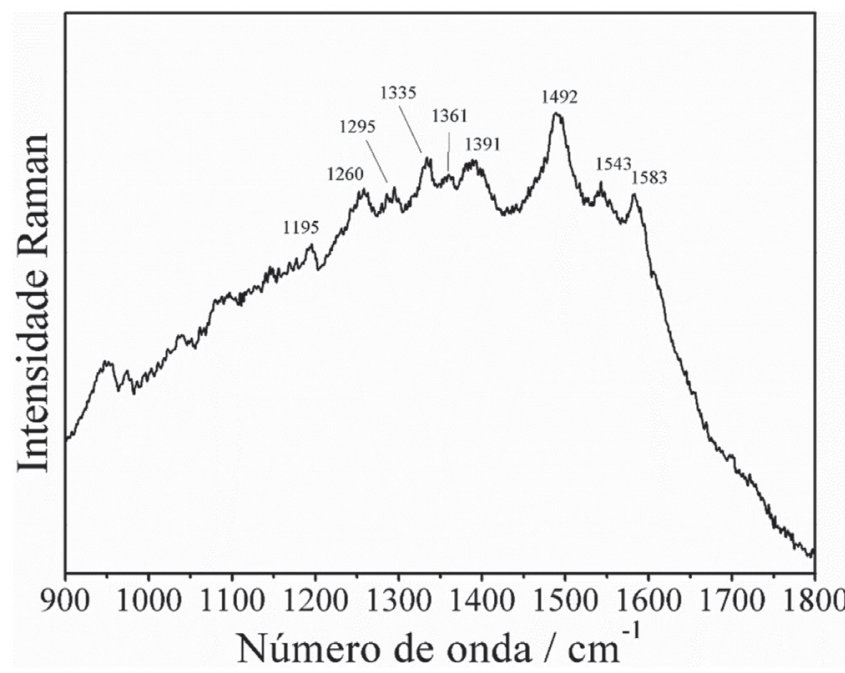

Figura 6. Espectro Raman $\left(\lambda_{0}=785 \mathrm{~nm}\right)$ do material eflorescente coletado na camada pictórica azul (Eflorescência_Azul2) da obra "Barco com bandeirinhas e pássaros". O espectro foi registrado após o recobrimento da amostra com ouro

As diferenças observadas entre os resultados obtidos na análise do material eflorescente amostrado na primeira coleta (material proteico, $\mathrm{CaSO}_{4}, \mathrm{CaCO}_{3}$ e $\left.\mathrm{CaMg}\left(\mathrm{CO}_{3}\right)_{2}\right)$ e na análise do material esbranquiçado coletado na segunda amostragem (padrão espectral similar ao de leveduras), permitem supor que se trata de processos distintos de degradação: um caracterizado pela migração de substâncias da camada de preparação da tela para a superfície da camada pictórica, contendo inclusive aglutinante proteico, e outro envolvendo a colonização microbiológica favorecida pela disponibilidade de nutrientes fornecidos pelo material proteico existente na pintura.

Avaliando o conjunto de resultados obtidos por espectroscopia Raman na investigação das eflorescências na pintura em têmpera "Barco com bandeirinhas e pássaros", a potencialidade da espectroscopia Raman em fornecer informações que contemplam a complexidade química intrínseca aos processos de degradação é demonstrada, tanto na capacidade de identificar substâncias orgânicas (aglutinantes) e inorgânicas (pigmentos e cargas), quanto na obtenção de indicativos da presença de micro-organismos. Essa versatilidade contribui significativamente para a compreensão de diferentes eventos envolvidos nos processos de degradação ao longo do tempo.

Dependendo do tipo de técnica empregada por um artista na confecção de uma pintura, a heterogeneidade desses sistemas a nível microscópico, por vezes, se apresenta como um desafio na detecção das substâncias, trazendo a necessidade do emprego de técnicas de alta sensibilidade. Nesse sentido, cabe destacar o uso de microscópios acoplados a espectrômetros Raman (microscopia Raman), que tem se mostrado bastante eficiente por proporcionar alta resolução lateral (da ordem de micrômetros) capaz de distinguir substâncias em fases heterogêneas, mesmo em quantidades mínimas. Um exemplo dessa vantagem é apresentado no caso da investigação da pintura mural da Sala do Trono do Palácio Nacional de Mafra, considerando as características dos microfragmentos da camada pictórica da pintura (Figura 1S, Material Suplementar).

Nesse contexto, a necessidade de caracterizar os materiais empregados na confecção de uma pintura leva em consideração que processos de decaimento advêm, frequentemente, da interação entre diferentes substâncias e/ou delas com o meio, de modo que o entendimento da sua composição pode ser um fator chave para a compreensão dos processos de degradação em curso.

Levando em conta as heterogeneidades evidenciadas por microscopia óptica dos microfragmentos da camada pictórica da pintura (Figura 1S, Material Suplementar), a análise por microscopia Raman permitiu identificar a mistura de pigmentos hematita $(223,293,408,495,610$ e $1310 \mathrm{~cm}^{-1}$ ) e vermelhão ( $\mathrm{HgS}, 252,284$ e $\left.343 \mathrm{~cm}^{-1}\right)$ na composição da camada pictórica vermelha (VermP, espectros na Figura 7) e a mistura de pigmentos azul ultramarino $\left(546 \mathrm{~cm}^{-1}\right)$, goetita $(243,298,391$ e 543 $\left.\mathrm{cm}^{-1}\right)^{27}$ e amarelo de crômio $\left(\mathrm{PbCrO}_{4}, 358 \text { e } 838 \mathrm{~cm}^{-1}\right)^{28}$ na composição da camada pictórica verde (VP, espectros na Figura 8). Além disso, foi possível identificar amarelo de crômio na camada pictórica amarela (AmP, espectro na Figura 7), com bandas características em 358 e $840 \mathrm{~cm}^{-1},{ }^{28}$ e pigmento azul ultramarino na camada pictórica azul (AP, espectro na Figura 7), com banda característica em $546 \mathrm{~cm}^{-1} .^{29}$

É interessante notar que a presença do pigmento amarelo $\mathrm{PbCrO}_{4}$ sugere anterior intervenção de restauro, uma vez que este pigmento foi introduzido em 1809 e disponibilizado comercialmente a partir de $1815^{30}$ (datas posteriores à data de finalização da pintura, 1807). O diagnóstico de anterior intervenção de restauro, por sua vez, permite supor que a degradação observada pode ser recorrente.

Além das já mencionadas vantagens do uso da espectroscopia vibracional em bens culturais, como seu caráter virtualmente não invasivo, merece destaque a complementaridade existente entre a espectroscopia Raman e a espectroscopia de absorção no infravermelho, ${ }^{31}$ que consiste no fato de que transições permitidas em uma podem não sê-lo na outra, o que atribui uma grande vantagem na união dessas técnicas na investigação de diferentes substâncias em matrizes complexas. Um exemplo da aplicação direta desse princípio, nos estudos aqui apresentados, é a identificação do meio aglutinante empregado na produção das tintas da pintura mural da Sala do Trono do Palácio Nacional de Mafra, que complementa a caracterização dos pigmentos obtida por microscopia Raman. Nesse estudo, a substância aglutinante empregada foi identificada como óleo, como mostra o espectro $\mu$-FTIR da amostra AmP (camada pictórica amarela), na Figura 9-acima. Nesse caso, a presença de óleo na composição da camada pictórica é evidente pela observação das bandas em 2927 e $2854 \mathrm{~cm}^{-1}$ (estiramento C-H) e $1741 \mathrm{~cm}^{-1}$ (estiramento $\mathrm{C}=\mathrm{O}$ ), típica desses compostos, ${ }^{32}$ embora o tipo específico de óleo seja dificilmente distinguido pela técnica devido à similaridade de composição dessas substâncias. ${ }^{33}$

É oportuno destacar que quando se objetiva a identificação do tipo de óleo usado na produção de tintas, técnicas destrutivas e que demandam maior quantidade de amostra, como cromatografia gasosa acoplada a espectrometria de massa (GC-MS), devem ser usadas para estimar as frações de ácidos graxos que caracterizam determinados óleos vegetais.

Outra vantagem oferecida pela espectroscopia FTIR é demonstrada na análise das eflorescências coletadas da pintura mural, uma vez que o material apresentou grande luminescência, impedindo a observação do espectro Raman. Na análise dos materiais eflorescentes (Sais 1, 2 e 3) por $\mu$-FTIR (espectro da amostra Sais 1 na Figura 9 - abaixo), $\mathrm{CaSO}_{4} \cdot 2 \mathrm{H}_{2} \mathrm{O}$ (gesso) foi identificado como o composto majoritário pela presença de bandas da água em aproximadamente $3526\left(v_{3}\right.$, estiramento antissimétrico $\left.\mathrm{O}-\mathrm{H}\right), 3393 \mathrm{~cm}^{-1}\left(\mathrm{v}_{1}\right.$, estiramento simétrico O-H), 1682 e 1619 cm$^{-1}$ (deformação angular O-H; frequências relativas a moléculas de água em duas diferentes simetrias), ${ }^{34}$ e do íon sulfato em $1115 \mathrm{~cm}^{-1}\left(v_{3}\right.$, estiramento antissimétrico $\left.\mathrm{S}-\mathrm{O}\right)$ 

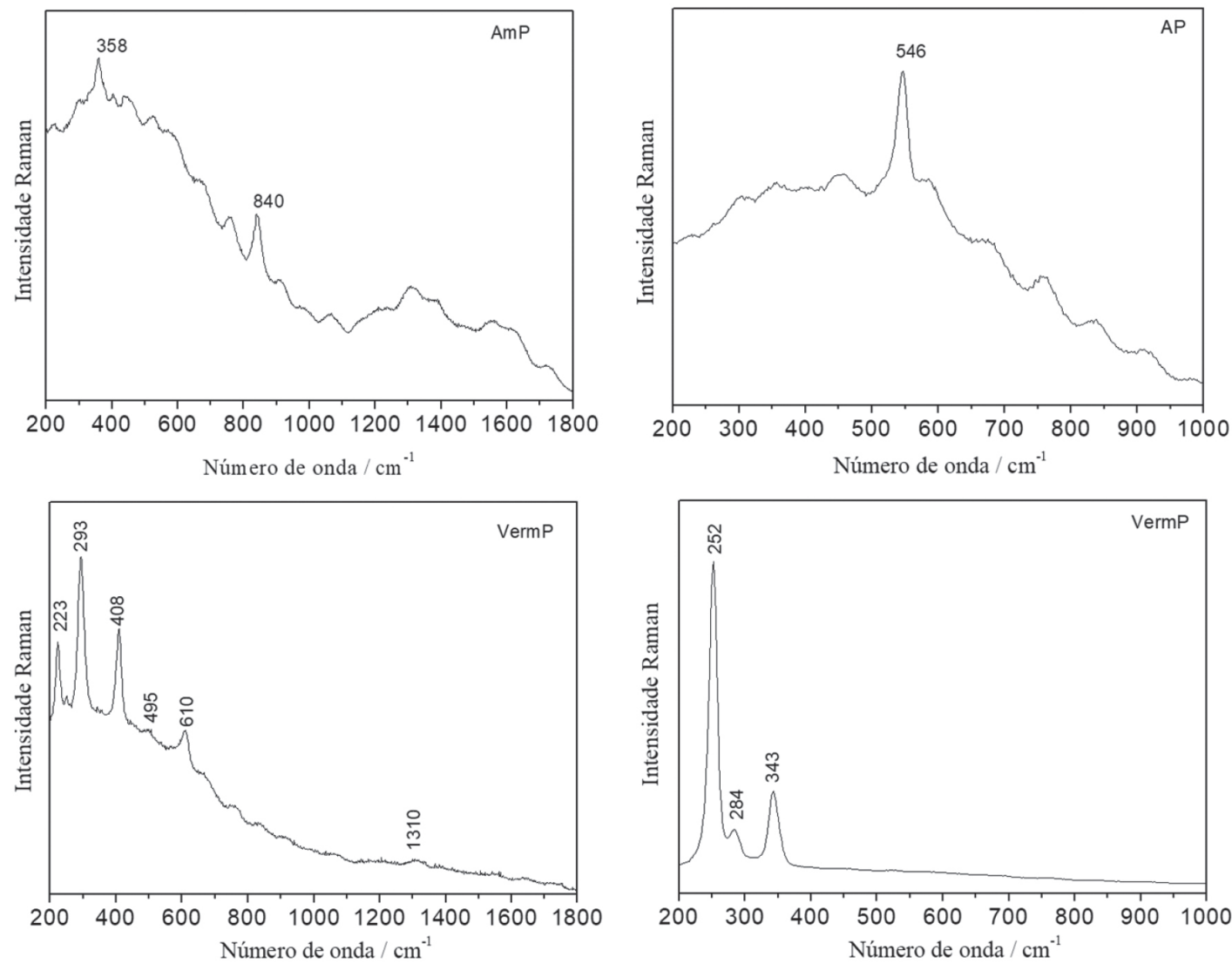

Figura 7. Espectro Raman $\left(\lambda_{0}=785 \mathrm{~nm}\right)$ dos microfragmentos das camadas pictóricas amarela $(\mathrm{AmP})$, azul $($ AP) e vermelha (VermP) da região degradada da pintura mural
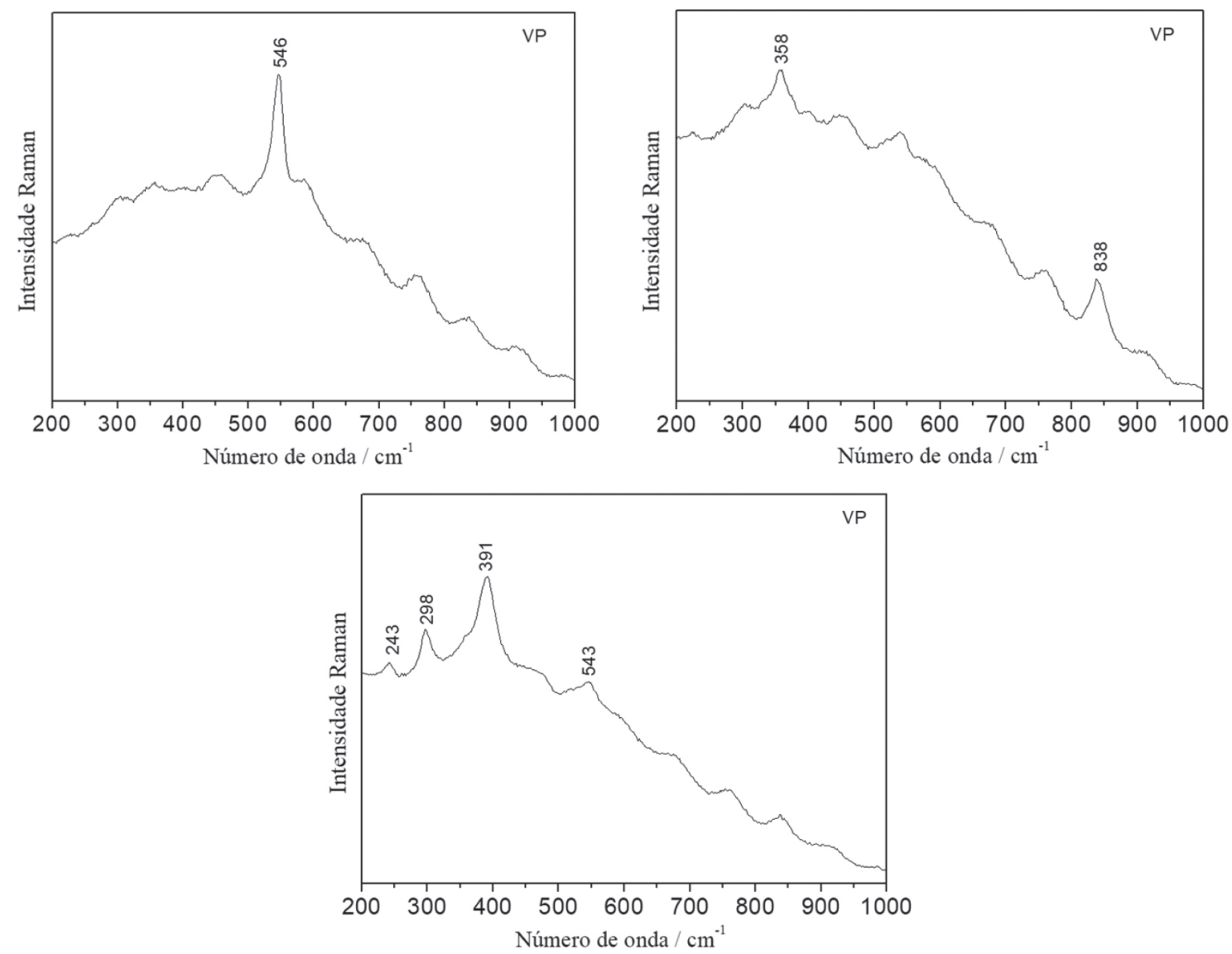

Figura 8. Espectros Raman $\left(\lambda_{0}=785 \mathrm{~nm}\right)$ do microfragmento da camada pictórica verde $(V P)$ da região degradada da pintura mural 

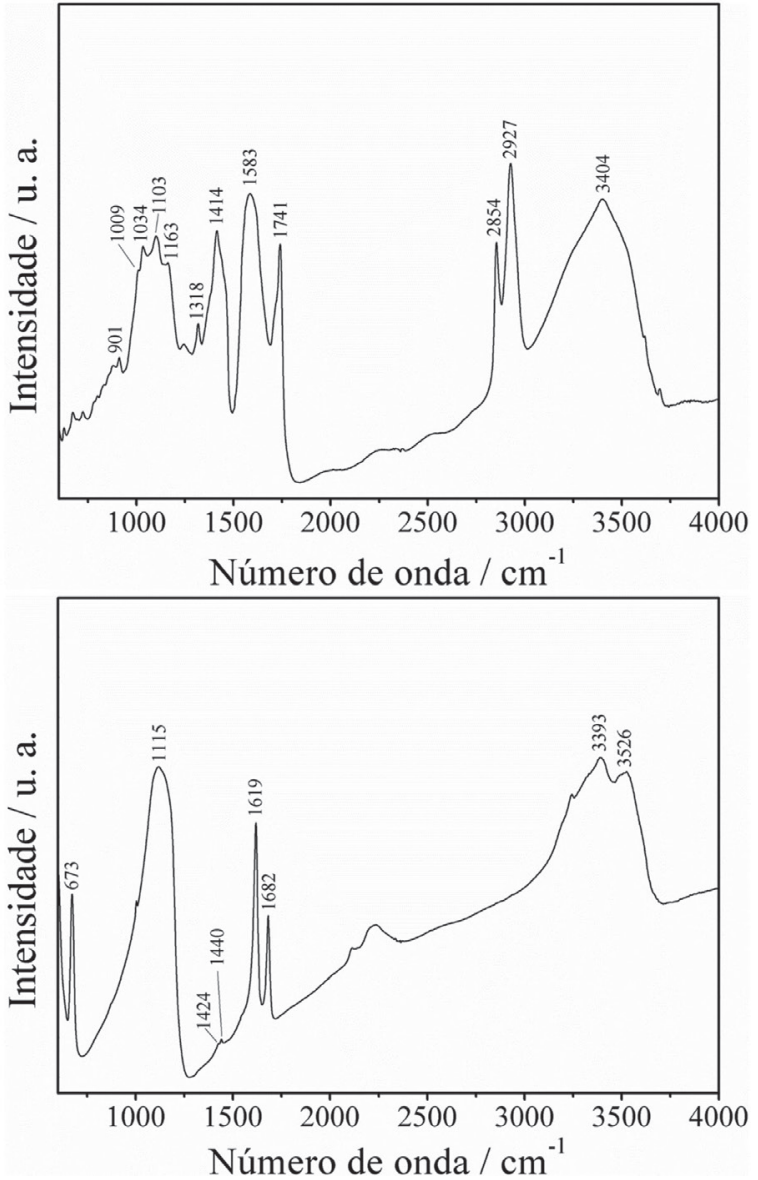

Figura 9. Acima, espectro $\mu$-FTIR do microfragmento da camada pictórica amarela $(\mathrm{AmP})$ da região degradada da pintura mural; abaixo, espectro $\mu$-FTIR de eflorescências salinas coletadas nas regiões degradadas da pintura mural

e $673 \mathrm{~cm}^{-1}$ (deformação angular S-O); ${ }^{35}$ essa identificação foi confirmada por XRD (valores característicos de $2 \theta$ em 20, $8^{\circ}, 29,2^{\circ}$, $31,1^{\circ}, 32,0^{\circ}, 33,4^{\circ}, 36,0^{\circ}, 40,7^{\circ}$ e $43,3^{\circ}$, não mostrado). A presença de um dubleto em aproximadamente $1441 \mathrm{e} 1424 \mathrm{~cm}^{-1}$ nos espectros $\mu$-FTIR das eflorescências (Figura 9 - abaixo) levantou, a princípio, a suspeita da presença de $\mathrm{CaCO}_{3}{ }^{36}$ na composição das eflorescências, atribuindo tal característica à diminuição da simetria das espécies
$\mathrm{CO}_{3}{ }^{2-}$ que leva à perda da degenerescência do modo $v_{3}$ (estiramento antissimétrico) duplamente degenerado ${ }^{37}$ o que é comum a polimorfos do carbonato de cálcio. No entanto, uma separação de tal magnitude (aproximadamente $15 \mathrm{~cm}^{-1}$ ) é comparativamente discreta em relação ao observado para os polimorfos de $\mathrm{CaCO}_{3}$ (aproximadamente $27 \mathrm{~cm}^{-1}$ para a forma vaterita, e aproximadamente $50 \mathrm{~cm}^{-1}$ para a forma aragonita) ${ }^{38}$ considerando ainda a pequena intensidade das duas bandas não é possível afirmar a partir dos espectros FTIR que carbonato de cálcio esteja presente nas eflorescências salinas.

Como já demonstrado, a caracterização das heterogeneidades da composição em bens culturais contribui sensivelmente para a compreensão dos processos de degradação que possam estar em curso. Essa heterogeneidade, entretanto, algumas vezes só pode ser verificada em escala nanométrica, o que não é possível com o uso de técnicas baseadas em microscopia óptica devido à limitação da resolução na obtenção de imagens (dado pelo limite de difração de Bragg). Nesse cenário, a microscopia eletrônica de varredura (SEM) se apresenta como uma excelente alternativa, considerando sua capacidade de obter informações topográficas e morfológica com resolução de poucas dezenas de nanômetros, explorando fenômenos associados à interação do feixe de elétrons com a matéria.

Na complementação dos resultados obtidos na investigação das eflorescências na pintura "Barco com bandeirinhas e pássaros", por exemplo, a amostra Eflorescência_Azul2, que apresentou espectro Raman similar ao de leveduras, foi submetida à análise SEM, com as micrografias obtidas (Figura 10) revelando a presença de estruturas ovaladas e circulares, bastante similares à estrutura deste micro-organismo. ${ }^{39}$

É importante destacar que, apesar dos resultados concordantes de microscopia Raman e SEM, o diagnóstico em apenas um dos pontos de coleta (amostra Eflorescência_Azul2) não pode ser considerado suficiente para comprovar a hipótese de colonização microbiológica. Além disso, as condições de não assepsia empregadas na coleta do material eflorescente na pintura "Barco com bandeirinhas e pássaros" não permitem excluir que os micro-organismos identificados tenham sido introduzidos na amostra por contaminação ambiental. Considerase, entretanto, que a presença desses organismos nesse estudo de caso, especificamente, não teve papel relevante no desencadeamento da eflorescência observada, de maneira que a impossibilidade da confirmação inequívoca de sua origem não invalida a relevância desses resultados na demonstração da pontencialidade das técnicas utilizadas na identificação de micro-oganismos em situações em que não há material suficiente para a cultura microbiológica.

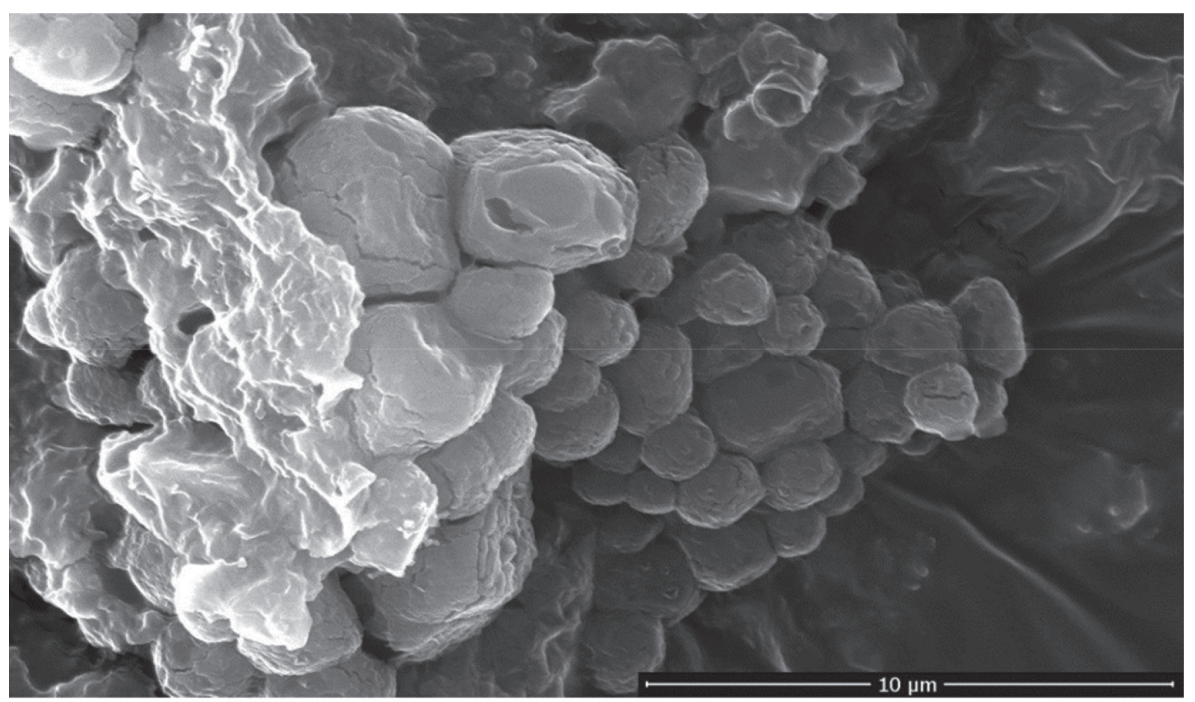

Figura 10. Micrografias SEM do material coletado da superfície da camada pictórica (Azul 1) da obra "Barco com bandeirinhas e pássaros" 
Em contraste, situação mais favorável ao diagnóstico de colonização microbiológica foi verificada para a pintura mural do Palácio Nacional de Mafra, uma vez que a análise SEM dos materiais coletados revelou grande quantidades de hifas fúngicas, como mostrado na Figura 11 (micrografia da camada pictórica verde, VP).

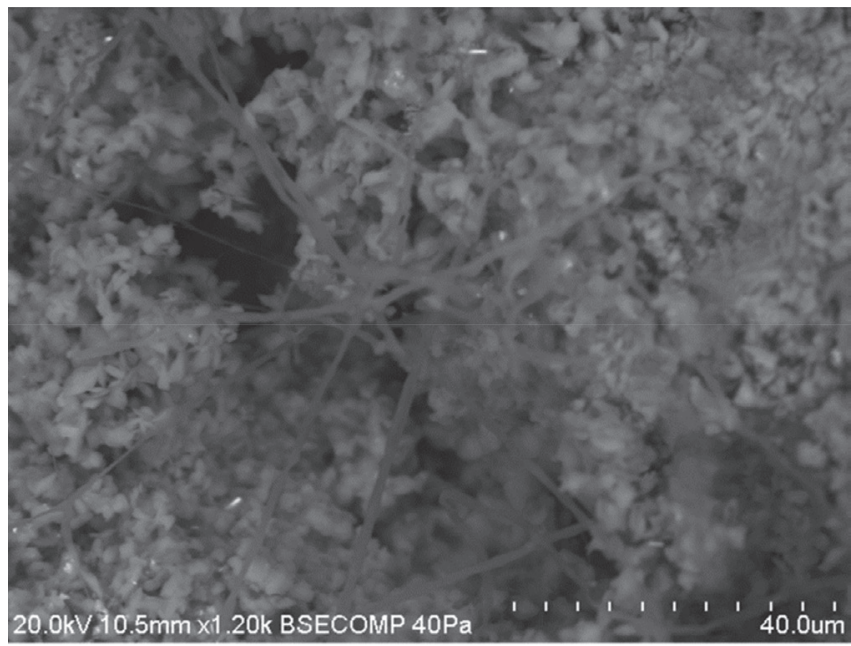

Figura 11. Micrografias SEM do microfragmento da camada pictórica verde (VP) coletado na pintura mural da Sala do Trono do Palácio Nacional de Mafra

Corroborando os resultados obtidos por SEM para a pintura mural, a análise microscópica de isolados microbiológicos proveniente da amostra Bio-Sais revelou a presença de fungos do gênero Cladosporium, com a identificação de hifas castanhas septadas, conidióforos eretos e pigmentados, e conídios alongados (Figura 2S, Material Suplementar). ${ }^{40}$

Frequentemente, na avaliação de mecanismos de degradação, o decaimento observado não pode ser associado a um único tipo de micro-organismo, estando geralmente associado a complexas interações microbiológicas, ${ }^{41}$ no entanto, as perdas materiais provocadas estão geralmente associadas à capacidade de penetração desses organismos em materiais porosos, o que leva à ruptura mecânica, ou à liberação de substâncias que promovem degradação (degradação enzimática e liberação de substâncias ácidas). ${ }^{42}$ Apesar de controvérsias acerca do papel dos fungos do gênero Cladosporium nos processos de biodeterioração, eles são descritos entre os fungos mais comuns associados à degradação de pinturas murais..$^{41,43}$

Além das características dos substratos, que depende da técnica usada pelo artista na confecção da pintura, a avaliação da susceptibilidade à biodeterioração também deve levar em conta fatores ambientais, como umidade e temperatura. ${ }^{43}$ Isso porque para que esses processos ocorram, condições favoráveis à proliferação devem ser garantidas. Em outras palavras, é justamente na correlação entre os fatores químicos, físicos e biológicos (identificação das espécies presentes) que uma melhor compreensão do desencadeamento e mecanismos de degradação pode ser atingida. ${ }^{41}$ Por exemplo, é conhecido que fungos do gênero Cladosporium necessitam de índices de $85 \%$ umidade relativa para colonização, ${ }^{44}$ de forma que sua detecção indica regiões de alta umidade.

\section{CONCLUSÕES}

$\mathrm{Na}$ investigação da pintura "Barco com bandeirinhas e pássaros", os resultados sugeriram que as eflorescências detectadas na primeira amostragem e o embranquecimento da superfície da camada pictórica observado posteriormente na segunda etapa da investigação, tenham se dado a partir de dois processos distintos de degradação: a migração de aglutinante da camada de preparação da tela e a colonização microbiológica. Já as eflorescências na pintura mural da Sala do Trono da Pintura Mural do Palácio Nacional de Mafra foram identificadas como eflorescências salinas (majoritariamente $\mathrm{CaSO}_{4} \cdot 2 \mathrm{H}_{2} \mathrm{O}$ ), nas quais se observou a presença de fungos do gênero Cladosporium. Devido à correlação da presença desse gênero de fungo com os conhecidos altos índices de umidade relativa $(85 \%)$ necessário para a sua proliferação, os resultados obtidos na investigação da pintura mural constituem um excelente exemplo de como a caracterização da composição das eflorescências podem fornecer informações importantes para inferir as condições ambientais às quais a obra está exposta, o que deve contribuir para o estabelecimento de estratégias de intervenção e de conservação preventiva dos bens.

Finalmente, o conjunto de resultados e a tentativa de interpretação dos fenômenos observados demonstraram a importância de conhecer quimicamente os sistemas investigados para aprofundar a compreensão dos fatores intrínsecos e extrínsecos que afetam os processos de degradação.

\section{MATERIAL SUPLEMENTAR}

Imagens de microscopia óptica de campo escuro dos cortes estratigráficos das camadas pictóricas coletadas da Sala do Trono do Palácio Nacional de Mafra, e fotografias dos isolados microbiológicos presentes na amostra Bio-Sais, coletada na região degradada da pintura mural, estão disponíveisem http://quimicanova.sbq.org.br, na forma de arquivo PDF, com acesso livre.

\section{AGRADECIMENTOS}

Os autores agradecem à CNPq pela bolsa concedida (159176/2013-1) e à FAPESP pelo suporte financeiro (2012/131193 e 2016/21070-5).

Projeto "M3DUSA - Microorganisms Monitoring and Mitigation - Developing and Unlocking novel Sustainable Approaches" (ALT2003-0145-FEDER-000015) financiado pelo programa Alentejo2020.

Projeto DB-Heritage - Base de dados de materiais de construção.

\section{REFERÊNCIAS}

1. https://www.iccrom.org/section/heritage-science, acessada em setembro 2019.

2. Caldararo, N. L.; J. Am. Inst. Conserv. 1987, 26, 85.

3. Artioli G.; Angelini, I.; Scientific Methods and Cultural Heritage, Oxford University Press: New York, 2010.

4. Cappitelli, F.; Fermo, P.; Vecchi, R.; Piazzalunga, A.; Valli, G.; Zanardini, E.; Sorlini, C.; Water, Air, Soil Pollut. 2009, 201, 109.

5. Cataldo, R.; De Donno, A.; De Nunzio, G.; Leucci, G.; Nuzzo, L.; Siviero, S.; Journal of Cultural Heritage 2005, 6, 29.

6. Ordonez, E.; Twilley, J.; Anal. Chem. 1997, 69, 416.

7. Sawicka, A.; Burnstock, A.; Izzo, F. C.; Keune, K.; Boon, J. J.; Kirsch, K.; van den Berg, K. J. In Issues in Contemporary Oil Paint, van den Berg, K. J., Burnstock, A., de Keijzer, M., Krueger, J., Learner, T., de Tagle, A., Heydenreich, G., eds.; Springer: Cham, 2014.

8. Learner, T.; Learner, T. J.; Smithen, P.; Krueger, J. W.; Schilling, M. R.; Modern paints uncovered: proceedings from the modern paints uncovered symposium. London, United Kingdom, 2007.

9. Tumosa, C. S.; Mecklenburg, M. F; Proceedings from the Cleaning 2010 International Conference, Universidad Politecnica de Valencia and Museum Conservation Institute, Smithsonian Institution, Washington DC, 2013. 
10. Bartl, B.; Havlín, J.; Trejbal, J.; Ďurovič, M.; Thermochim. Acta 2013, 566, 292.

11. Van Loon, A.; Molart Report 2008, 14, 119.

12. Puglieri, T. S.; Lavezzo, A. S.; dos Santos, I. F.; de Faria, D. L.; Spectrochim. Acta, Part A 2016. 159, 117.

13. Gornall, A. G.; Bardawill, C. J.; David, M. M.; J. Biol. Chem. 1949, 177, 751.

14. Rosado, T.; Gil, M.; Mirão, J.; Candeias, A.; Caldeira, A. T.; Int. Biodeterior. Biodegrad. 2013, 85, 1.

15. Valenzano, L.; Noel, Y.; Orlando, R.; Zicovich-Wilson, C. M.; Ferrero, M.; Dovesi, R.; Theor. Chem. Acc. 2007, 117, 991.

16. Herman, R. G.; Bogdan, C. E.; Sommer, A. J.; Simpson, D. R.; Appl. Spectrosc. 1987, 41, 437.

17. Revista Arte Hoje, Ano 2, $\mathrm{N}^{\circ} 13,1978$.

18. Mori, E. K.; Dissertação de Mestrado, Universidade de São Paulo, Brasil, 2015.

19. Nevin, A.; Osticioli, I.; Anglos, D.; Burnstock, A.; Cather, S.; Castellucci, E.; J. Raman Spectrosc. 2008, 39, 993

20. Elert, K.; Herrera, A.; Cardell, C.; Dyes Pigm. 2018, 148, 236.

21. Vandenabeele, P.; Wehling, B.; Moens, L.; Edwards, H. E.; De Reu, M.; Van Hooydonk, G.; Anal. Chim. Acta, 2000, 407, 261.

22. Sarma, L.; Prasad, P.; Ravikumar, N.; J. Raman Spectrosc. 1998, 29, 851.

23. Clark, R.; Franks, M.; Chem. Phys. Lett. 1975, 34, 69.

24. Vandenabeele, P.; Verpoort, F.; Moens, L.; J. Raman Spectrosc. 2001, $32,263$.

25. Smith, W.; Chem. Soc. Rev. 2008, 37, 955.

26. Sujith, A.; Itoh, T.; Abe, H.; Yoshida, K. I.; Kiran, M. S.; Biju, V.; Ishikawa, M.; Anal. Bioanal. Chem. 2009, 394, 1803.

27. de Faria, D. L. A.; Lopes, F. N.; Vib. Spectrosc. 2007, 45, 117.

28. Monico, L.; Janssens, K.; Hendriks, E.; Brunetti, B. G.; Miliani, C.; J. Raman Spectrosc. 2014, 45, 1034.
29. Osticioli, I.; Mendes, N. F. C.; Nevin, A.; Gil, F. P.; Becucci, M.; Castellucci, E.; Spectrochim. Acta, Part A 2009, 73, 525.

30. Amat, A.; Miliani, C.; Fantacci, S.; Royal Soc. Chem. Adv. 2016, 6, 36336.

31. Daher, C.; Paris, C.; Le Hô, A. S.; Bellot-Gurlet, L.; Échard, J. P.; J. Raman Spectrosc. 2010, 41, 1494.

32. Manfredi, M.; Barberis, E.; Rava, A.; Robotti, E.; Gosetti, F.; Marengo, E.; Anal. Methods 2015, 7, 2313.

33. Rohman, A.; Int. J. Food Prop. 2017, 20, 1447.

34. Mandal, P.K.; Mandal, T. K.; Cem. Concr. Res. 2002, 32, 313.

35. Liu, Y.; Wang, A.; Freemen, J. J.; Resumos da $40^{\text {th }}$ Lunar and Planetary Science Conference, The Woodlands (Texas), EUA, 2009.

36. Gunasekaran, S.; Anbalagan, G.; Pandi, S.; J. Raman Spectrosc. 2006, 37, 892 .

37. Weir, C. E.; Lippincott, E. R.; J. Res. Natl. Bur. Stand., Sect. A 1961, 65, 173.

38. Andersen, F.A.; Brecevic, L.; Acta Chem. Scand. 1991, 45, 1018.

39. Wright, R.; Microsc. Res. Tech. 2000, 51, 496.

40. Barnett, H. L.; Hunter, B. B.; Illustrated Genera of Imperfect Fungi. Burgess Publishing Company. 4third Edition, Minnesota, 1986

41. Unković, N.; Grbić, M. L.; Stupar, M.; Savković, Ž.; Jelikić, A.; Stanojević, D.; Vukojević, J.; Microsc. Microanal. 2016, 22, 410.

42. Sterflinger, K.; Piñar, G.; Appl. Microbiol. Biotechnol. 2013, 97, 9637.

43. Nugari, M. P.; Realini, M.; Roccardi, A.; Aerobiologia 1993, 9, 131.

44. Guerra, F. L.; Lopes, W.; Cazarolli, J. C.; Lobato, M.; Masuero, A. B.; Dal Molin, D. C.; Bento, F. M.; Schrank, A.; Vainstein, M. H.; Build. Environ. 2019, 155, 195.

FAPESP contribuiu para custear a publicação deste artigo. 